\title{
LA INFORMACIÓN RELIGIOSA EN LA PRENSA DE MURCIA DURANTE LA SEGUNDA REPÚBLICA Y LA GUERRA CIVIL
}

POR

\author{
Francisca Colomer Pellicer
}

IES Santa María de los Baños. Fortuna. Murcia

\begin{abstract}
RESUMEN
Durante los afios de la segunda República la sociedad murciana se fue politizando paulatinamente, lo que tiene sus consecuencias directas sobre las informaciones religiosos que se incluyen en los medios, destacándose que existen diferencias comarcales muy marcadas en este proceso.
\end{abstract}

\section{Abstract}

During the years of the second Republic the society of Murcia was polityzaded gradually, with direct consequences on the religious information that are included in the medias. In fact there are local differences in this process.

\section{INTRODUCCIÓN}

Cuando las personas que componen una sociedad se toman en serio su función en ella, procuran que sus ideas salgan a la luz a través de medios adecuados, como son la prensa y otros medios de comunicación. A través de ellos podemos conocer el latido de una sociedad, tomarle el pulso, comprender sus ideales y sus luchas, intuir su composición y su estructura interna.

Con esta finalidad he estudiado todas las publicaciones que hay en Murcia en los periodos de la Segunda República y la Guerra Civil. Esta investigación está dentro de otra más amplia, cuya finalidad es conocer la evolución de la mentalidad de la sociedad murciana durante los siglos XIX y XX. 
1. Clasificación de la prensa de MurCia, 1931-1939

En la Hemeroteca Municipal de Murcia hay catalogadas 68 publicaciones pertenecientes al periodo que nos ocupa. De ellas, dos se refieren directamente a Murcia pero han sido publicadas fuera de ella, y por tanto no las incluimos en nuestro estudio. Son La Región de Murcia, Boletín de la Casa Regional de Albacete y Murcia en Barcelona; y Cromos, una revista ilustrada de Madrid que dedica su número 5 a Murcia.

He clasificado estas publicaciones en seis grupos: prensa católica (25\%), prensa espiritual (11\%), prensa independiente (33\%), prensa de derechas $(5 \%)$, prensa de izquierdas (18\%), y prensa laicista ( $8 \%$ ). Estos nombres necesitan una explicación.

IDEOLogía DE LA PRENSA DE MURCIA, 1931-1939

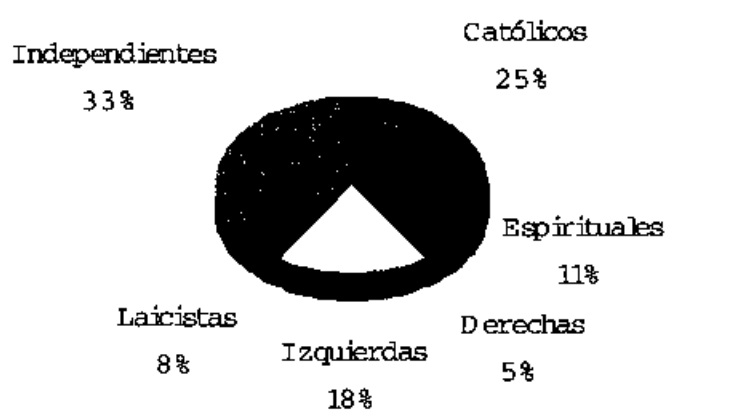

He llamado prensa católica a aquellas publicaciones que son órganos oficiales de asociaciones o sindicatos católicos, publicaciones de parroquias y del obispado, o las respaldadas por editoriales que buscan difundir en la sociedad la doctrina católica. Dentro de este grupo parece que debería estar la prensa que he llamado «espiritual». Pero éstas son publicaciones que buscan solamente mover la piedad de sus lectores, enfervorizarlos religiosamente; no tienen como finalidad formar las inteligencias de los ciudadanos ante la situación socio-política, ni animan a participar en la vida de la sociedad con los ideales cristianos. Por este motivo las he considerado un grupo aparte. Pero hay que tener en cuenta que si sumamos los porcentajes de la prensa católica y la espiritual, la prensa religiosa es mayoría en Murcia (36\%).

La prensa de izquierdas está formada por los periódicos editados por los partidos y sindicatos de izquierdas (PC, PSOE, CNT, UGT), al igual que la prensa

Actas del I Congreso de Historia de la Iglesia y el Mundo Hispánico Hispania Sacra, 52 (2000) 
de derechas, que está respaldada por los tradicionalistas o por Acción Popular. Para evitar la asimilación de los republicanos con los anticlericales, he elegido el nombre de «laicista», muy común en aquellos días, para designar al conjunto de publicaciones que atacan o ridiculizan a la Iglesia Católica, aunque sus líneas editoriales sean variadas.

Todas las publicaciones que no cumplían alguno de estos requisitos han pasado a formar parte del gnupo de «prensa independiente». Para hacer justicia a su variedad lo he dividido en seis categorias: prensa cultural, prensa puramente informativa, prensa deportiva, prensa de asociaciones profesionales, prensa de asociaciones varias, prensa de crítica política.

\section{CATEGORTAS DE LA PRENSA INDEPENDIENTE}

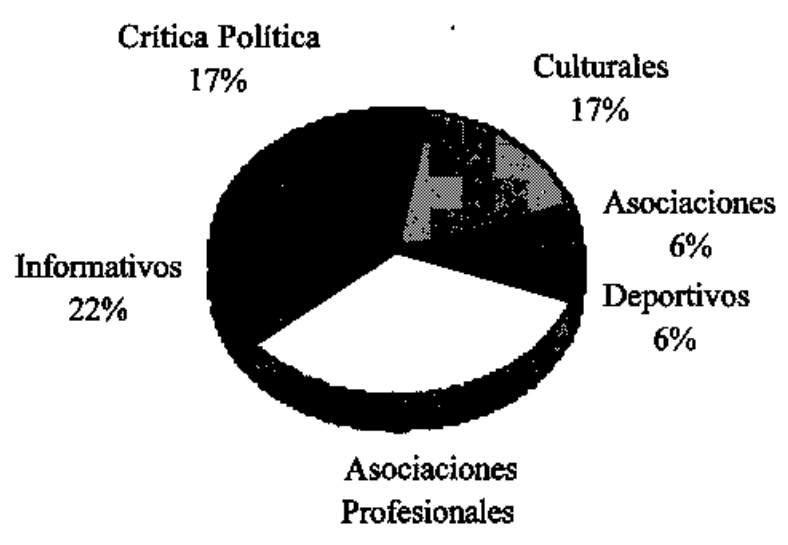

\section{Distribución geográfICA de LA PRENSA de MuRCia}

El estudio está centrado en la actual Comunidad autónoma de la Región de Murcia, con exclusión de Cartagena y su comarca, que es objeto de otro trabajo. Es decir, no he tenido en cuenta las publicaciones de la provincia de Albacete, que en la época de nuestra investigación formaba parte de la Región de Murcia.

Con un $69 \%$, Murcia capital es la ciudad con más publicaciones de la Región, lo cual es lógico debido a su condición de capital y al número de habitantes. Las demás poblaciones que se reseñan cuentan con 1, 2, 3 ó 4 publicaciones. 


\section{Prensa en la Región de Murcia (excepto Cartagena)}
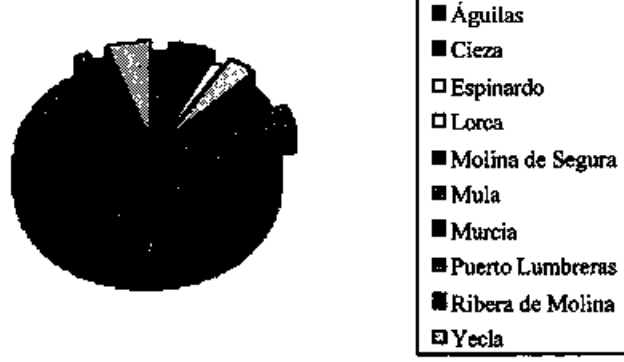

Águilas cuenta con una sola publicación, de carácter independiente. Cieza tiene tres: dos de derechas durante la República, y una de izquierdas durante la guerra. En Espinardo hay un periódico católico. En Lorca, uno laicista y otro católico. En Molina de Segura está más repartido: hay uno independiente, uno de izquierdas y uno católico. En Mula hay uno espiritual y uno de derechas. En Puerto Lumbreras el único periódico que hemos encontrado es republicano; en la Ribera de Molina, es espiritual, y de los tres de Yecla hay dos católicos y uno espiritual.

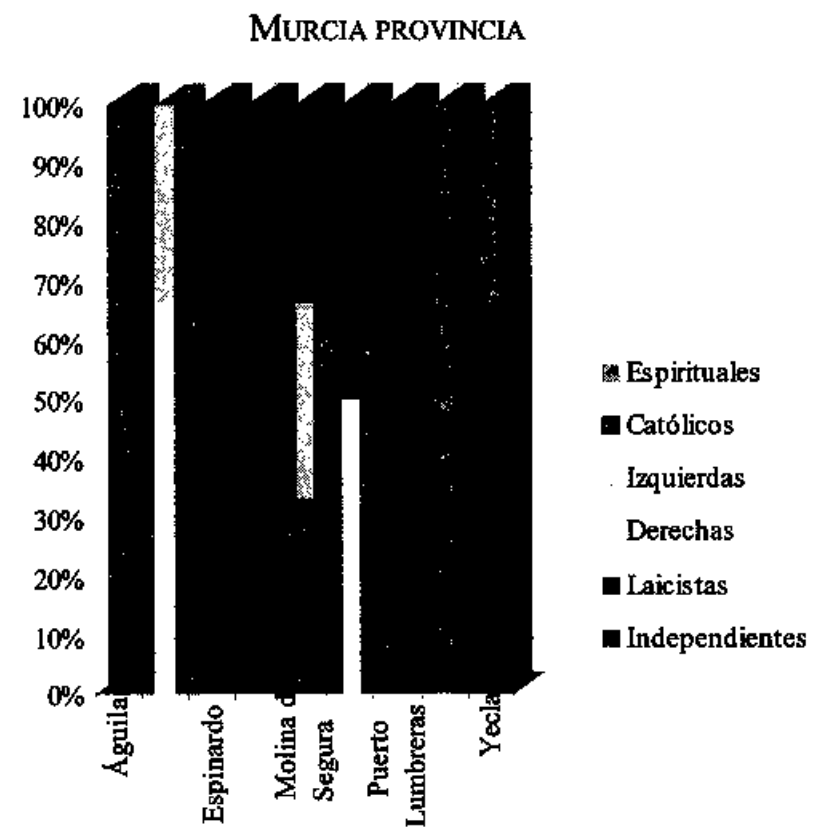

Actas del I Congreso de Historia de la Iglesia y el Mundo Hispánico Hispania Sacra, 52 (2000) 
En Murcia capital el panorama es más variado. De los 39 periódicos que se publican, 16 son independientes; 3 son laicistas; 6 de izquierdas, 10 son católi$\cos , 4$ son espirituales, $y$ ninguno de derechas.

\section{MURCIA CAPITAL}

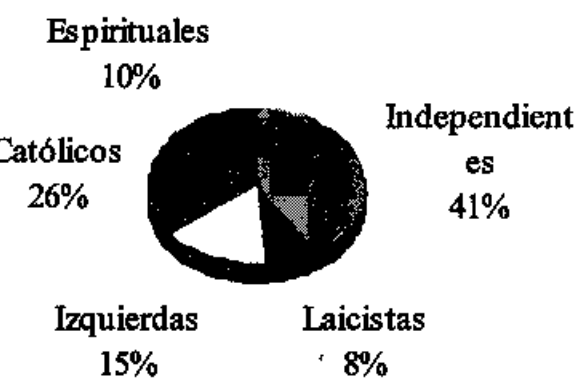

\section{FundACIÓN DE NUEVOS PERIódICOS}

Durante este periodo se mantienen publicaciones iniciadas en los afíos 19201930 , por lo que incluimos éstos en la tabla. A partir del advenimiento de la República se dispara la fundación de todo tipo de publicaciones. Los años de mayor fiebre divulgativa son los de $1932 \mathrm{y}$, con mucha diferencia, 1935, mientras que el mínimo lo comparten 1934 y 1938 , año este último en el que escasea el papel y algunas publicaciones tienen que cerrar por este motivo.

\section{FUNDACIÓN DE PERIÓDICOS POR AÑO}

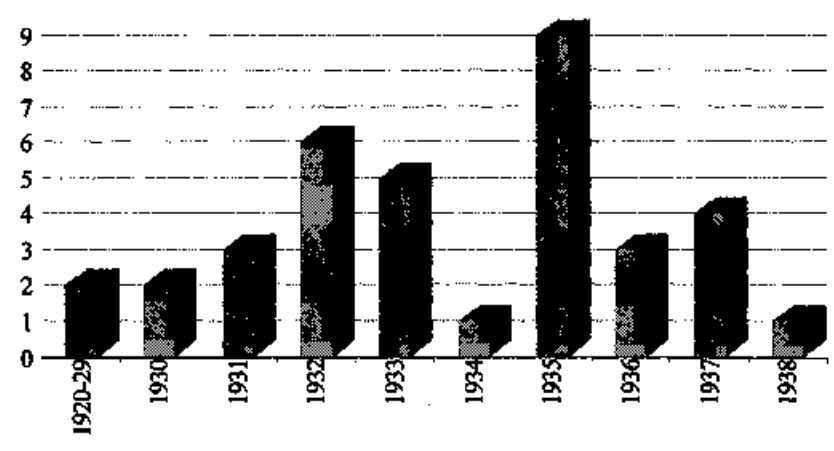

Actas del I Congreso de Historia de la Iglesia y el Mundo Hispánico Hispania Sacra, 52 (2000) 
Si comparamos los años de publicaciones con las ideologías de los periódi$c o s$, podemos sacar conclusiones interesantes. Hasta el año 30 el «mercado» está repartido casi a partes iguales entre la prensa espiritual y la de izquierdas, como si cada grupo se preocupara por su propia grey. A partir de 1930 comienza la lucha por la fundación de publicaciones y, por tanto, la captación de lectores. En ese año los nuevos periódicos son todos católicos o independientes. En el año 31 se fundan nuevos periódicos de estas dos tendencias, y aparecen los que hemos llamado laicistas; varios de estos periódicos profesan su fe republicana, lo que explica su surgimiento en este año. En el año 32 hacen su aparición las derechas, a la vez que se produce un aumento de la prensa católica y aparecen nuevos periódicos laicistas.

El affo 1933 es el del contraataque de las izquierdas, que fundan nuevos periódicos; también aparece prensa nueva independiente y espiritual, y disminuyen las fundaciones de prensa católica. 1934 es el año con menos novedades editoriales, pero todas ellas son independientes. Parece que es un descanso en la lucha del "cuarto poder».

1935, el año de la fiebre de novedades periodísticas, está en su mayoría protagonizado por la prensa independiente, pero también se fundan nuevos periódicos de derechas y católicos. El año 36 se producen nuevas fundaciones de prensa católica, pero desde el comienzo de la guerra y hasta el final de ésta, las nuevas publicaciones son todas de izquierdas.

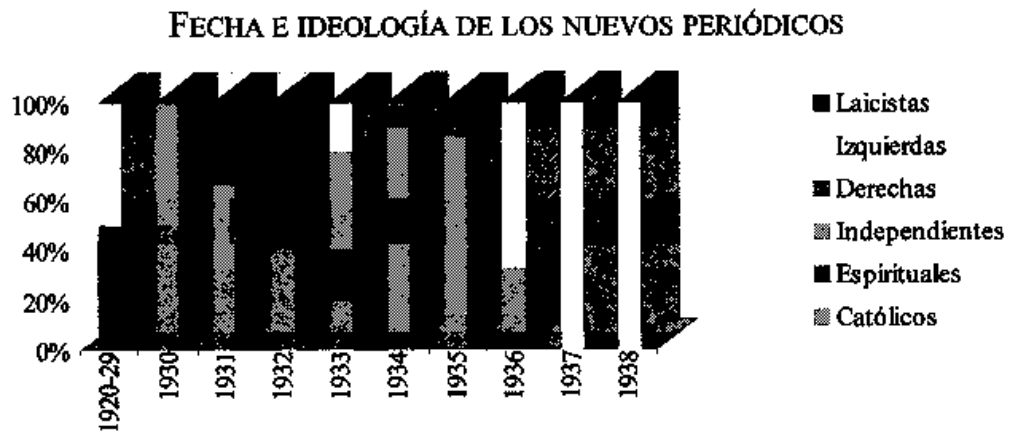

\section{CONTENIDOS DE LAS PUBlicaciones}

a) Prensa católica

La prensa católica es la de más amplio espectro. Excluyendo la prensa que he llamado «espiritual», encontramos al menos cinco tipos de publicaciones: 
a) Diarios de información de base católica, como $L A$ VERDAD $D^{1}$ y $E L T I E M-$ $P O^{2}$. Ambos contienen noticias respetuosas con la doctrina y la jerarquía, y artículos animando a luchar contra el socialismo. En sus números extraordinarios encontramos frecuentes alusiones a las bases cristianas de la región, tradiciones religiosas, lugares de devoción.

b) También hay varios semanarios que buscan con todo su afán la concienciación de los católicos ante la situación sociopolítica. EL HORIZONTE ${ }^{3}$, de Lorca, subtitulado «Semanario Católico-Social», en varios artículos anima a los católicos a unirse y que no avance más el anarcosindicalismo; alerta sobre el uso de las cuotas obreras que hacen los sindicatos (zurdos»; explica que la Iglesia es perseguida porque a su Luz los ateos no pueden abandonarse a sus propias pasiones. Incluye sonetos religiosos, noticias sobre las persecuciones a los cristianos, noticias candorosas -que se tienen por verdaderas- sobre sacrilegios cometidos por obreros descreidos y el consiguiente, fulminante y aleccionador castigo que han recibido de la Providencia. Aunque en la cabecera de este semanario no aparece filiación alguna, El Horizonte busca el voto para Acción Popular en las elecciones municipales de abril. «Acción Popular tiene encomendada la defensa de Religión, Patria, Propiedad, Orden y Familias, explica en un artículo.

Del mismo tipo es $L A$ DEFENSA ${ }^{4}$, Semanario Católico Independiente Portavoz de los Intereses de Molina, que comienza a publicarse en enero de 1932 y que, pese a sus protestas de independencia, se siente portavoz de Acción Nacional, si bien primando la defensa de la Religión Católica antes que los fines puramente políticos. En el número 1 hay un artículo de Elías Olmo titulado «El socialismo empobrece a los pueblos y arruina a las naciones»; y un comentario sobre el problema de los crucifijos en las escuelas. En el número dos recoge enérgicas protestas por la disolución de los jesuitas.

c) Publicaciones oficiales como el BOLETÍN OFICIAL ECLESIÁSTICO DEL OBISPADO DE CARTAGENA ${ }^{5}$, en cuyo n. 7 se publica una carta pastoral del nuevo obispo Díaz Gómara, titulada «La Vida Cristiana», que es un minucioso resumen de toda la teoría y la praxis de la vida sobrenatural; y DIÓCESIS $D E C A R T A G E N A^{6}$, boletin estadístico anual.

\footnotetext{
1 Archivo Histórico Municipal de Murcia (AHMM), 22-C-7.

2 AHMM, 220-A, B y C; AHMM, 25-B-17.

AHMM, 25-B-3.

AHMM, 25-B-3.

5 AHMM, 28-B-15.

AHMM, 28-B-16.
} 
No propiamente oficial, pero sí relacionada con la jerarqufa es el $E C O D E L$ $C L E R O^{7}$, revista sacerdotal, que sufre una significativa evolución entre el año 33 y el 35 . Los números 220 al 223 son un ejemplo de lucha por la unidad y formación intelectual de los sacerdotes. «Los actuales momentos de angustia por que atraviesa la clase sacerdotal, han puesto en peligro muchas cosas: ha producido como un espasmo en la vida eclesiástica, ha paralizado el movimiento de muchas empresas y por eso han temido algunos que una de las víctimas de la persecución fuera nuestra querida revista.

Mas esto no debía ocurrir (...). Todo lo contrario ( $\ldots$ ): ha de visitar la casa de todos los sacerdotes, enriquecida con los mejores tesoros de luz, de optimismo, de esperanzas; hay que procurar que su visita sea esperada en todas partes como la de un amigo carifioso que lleva noticias alentadoras, que aconseja en las dificultades de la vida, que arranque del ánimo el pesimismo que como espina cruel lacera muchos corazones sacerdotales (...)».

La encuadernación está cuidada, y contiene muchas llamadas al optimismo, a actuar, a la esperanza; ánimos para profundizar en el estudio y tener «prestigio científico") como modo mejor de hacer apología del cristianismo; orientaciones muy pedagógicas acerca de la catequesis, chistecillos sobre los ataques al clero que se están sufriendo, artículos sobre la actualidad (como la Ley sobre Confesiones y Congregaciones religiosas, la doctrina de la Iglesia sobre el matrimonio civil); cartas optimistas y cariñosas de sacerdotes mayores o antiguos profesores del seminario... y continuas llamadas de socorro en el plano económico.

Pero el n. 231 , de noviembre de 1935 , es totalmente distinto. Un pliego de papel sin pastas y sin alma, dividido por cuadros que, como si fueran anuncios, van dando noticias variadas. Un artículo de una serie titulada «Conferencias morales", que en latín explica la doctrina sobre el ministro de la Eucaristía, y un artículo de fondo sobre la Casa del Sacerdote y la indigencia en que se encuentra. No queda rastro del espíritu «familiar», optimista y animoso, de la altura intelectual de los números de 1930.

d) Algunas asociaciones oficialmente católicas crean órganos de expresión, para facilitar la propia organización y comunicación interna simplemente (como JUVENTUD ${ }^{8}$. Boletín del Centro de Formación Cultural de la Parroquia de $\mathrm{S}$. Antolín, fundado en 1935), o con la finalidad de influir en la sociedad. Entre estos últimos están UNIVERSIDAD ${ }^{9}$, Revista-órgano de la Federación de Estudiantes Católicos de Murcia; ORIENTE ${ }^{10}$, Órgano de la Juventud de Acción

\footnotetext{
7 AHMM, 28-D-6.

8 AHMM, 22-A-9.

9 AHMM, 28-D-8.

10 AHMM, 28-D-8.
}

Actas del I Congreso de Historia de la Iglesia y el Mundo Hispánico Hispania Sacra, 52 (2000) 
Católica de Espinardo; EL BARRIO DEL CARMEN"11, editado por la Comisión de Propaganda de la Asociación de Caballeros Carmelitanos; y ORIENTACIÓN CATÓLICA ${ }^{12}$, Órgano de la Institución Pontificia Acción Católica, de Yecla.

Orientación Católica contiene artículos de formación e información sobre la actuación de los católicos en la vida pública, sobre noticias que les afectan, como la Ley de Congregaciones Religiosas, y ánimos y arengas para influir en la sociedad. El Barrio del Carmen, además de la información necesaria para sus actividades de ayuda social, artículos sobre el barrio, poemas y literatura, incluye artículos de formación relacionados con la existencia de Dios. En el $n .{ }^{\circ} 1$, de mayo de 1932, «No hay Dios!» explica lo ilógico y cómodo del ateísmo, por reducción al absurdo, técnica que también se usa en los artículos en forma de diálogo del «Tío Juan Picardías», titulados «Dios existe» en el número 2, y en el de El Centinela, «Pruebas de que Dios existe», en el n. ${ }^{\circ} 3$. El número $4-\mathrm{y}$ último- de esta publicación saldrá el 16 de junio de 1936, y tiene mayor carga formativa. Contiene un saludo del nuevo cura regente de la parroquia del Carmen, una noticia sobre el nuevo Consiliario Nacional de la Juventud Católica Espatiola, y dos artículos de fondo, titulados: «Nuestro lema: Fe, Esperanza, Caridad», $\mathrm{y}$ «De Acción social. Las vocaciones eclesiásticas y nuestro barrio».

Oriente, fundada en 1936, es también un modo de comunicación de actividades y noticias internas de la juventud de Acción Católica en Espinardo, y artículos acerca del peligro que supone la situación política y socio-ideológica para la juventud. Pero también incluye un artículo sobre los cuarenta años de la enciclica Rerum Novarum y la doctrina social de Pío XI; otro sobre el cardenal Belluga que termina con una llamada al trabajo por Dios y la sociedad, y, en el número 2 y previsiblemente último, de mayo-junio del 36 , anima a ese trabajo con un editorial titulado «Cruzados de Cristo». Universidad se marca como meta la divulgación cultural y de los ideales de la Federación de Estudiantes Católicos. En su primer número de la Tercera Época («bajo el pabellón tricolor»), un artículo de F. Martínez y García («La libertad se ha hecho católica») defiende la actitud de los católicos, históricamente a favor de la libertad, en contra de lo hecho por Lutero, el Terror, y los que llama «de la acera de enfrente», es decir, las izquierdas. También incluye un articulo de Vázquez de Mella sobre la unidad de España gracias a la religión católica. Además de estos artículos de matiz partidista incluye alguna colaboración más pura de doctrina de la Iglesia como un poema de Sánchez Madrigal, titulado «La cuestión social», en contra de la lucha de clases y a favor de la caridad en las relaciones de clase.

\footnotetext{
" AHMM, 22-A-7 (1).

12 AHMM, 22-A-14.
} 
e) Por último nos quedan las publicaciones de sindicatos católicos. $L A$ VOZ OBRER $A^{13}$ de Murcia es el órgano de la Federación Regional de Sindicatos Católicos de Obreros, y empieza a publicarse en 1930. Sus fines son: Religión, Familia, Propiedad y Trabajo, amparar al obrero y la incondicional adhesión al Papa y al Obispo. Divulga la Doctrina Social de la Iglesia (en adelante, DSI) no solamente a través de los documentos magisteriales, sino también con propuestas concretas y explicaciones teóricas y comprometidas. Es muy claro. Muchas de esas explicaciones se hacen por contraposición al socialismo, como si, en vez de pretender formar cristianamente a los obreros, buscara evitar que acepten las doctrinas socialistas. Este modo de presentarse a la sociedad, en negativo, no debió favorecer mucho los buenos resultados de la innegable calidad de sus articulos.

También con la finalidad de divulgar la DSI aparece en 1933 en Yecla la hoja quincenal $O B R E R O S^{14}$, cuyo subtítulo dice: «Nuestra redención está en las doctrinas sociales de la Iglesia». Distinto matiz tiene EL DEFENSOR DE LA $O B R E R A^{15}$, boletín semestral de la Federación de Sindicatos Femeninos de Nuestra Señora de la Fuensanta, en Murcia. El número 4, de junio de 1936, bajo el lema «Paz, Justicia y Amon» contiene noticias de actividades, noticias políticas de dentro y fuera de España, artículos sobre la necesidad de asociarse para conseguir los fines, sobre el derecho al trabajo (atacando las posiciones de UGT y CNT), pero ningún artículo expreso de formación religiosa o de la DSI, aunque implícitamente está presente.

\section{b) Prensa espiritual}

Muchas asociaciones católicas tienen como finalidad mantener la piedad de sus asociados, sin comprometerse en más cuestiones ni sociales ni políticas, como puede verse en sus publicaciones. La HOJA DEL ASILO DE LA PURÍSIMA ${ }^{16}$ es el órgano de las asociaciones de Hijos e Hijas de María de dicho asilo. En 1931 ya iba por su año XXVIII. Las únicas alusiones a la situación del país se recogen en algunas pequeñas oraciones como «Sefiora, salvad a España», dos artículo titulados «Lo que no se enseña al pueblo», (que informa de las muertes violentas de los emperadores romanos que persiguieron a los cristianos), y «Camino de la Anarquía», poniendo ejemplos de la evolución política

${ }^{13}$ AHMM, 25-B-3.

14 AHMM, 22-A-9.

15 AHMM, 22-B-13 (10)

${ }^{16}$ AHMM, 22-A-7. 
última de algunos países europeos en los que ha ganado las elecciones la izquierda. Además hay otro rotulado "Guerra a la blasfemia».

Otros artículos ocasionales informan de la doctrina de la Iglesia, como los titulados «La Iglesia y los obreros», «Una encíclica para alentar y aleccionar a los católicos españoles», y un comentario defendiendo a la Iglesia de la acusación de haber escarnecido siempre a la mujer. Pero la mayor parte del contenido de la revista es puramente piadoso.

ACCION SOCIAL ANTONIANA ${ }^{17}$ también iba por su año VIII en 1931. En ningún momento se hace eco de la situación política; contiene simplemente artículos de formación piadosa, noticias de las labores sociales de los franciscanos en el Tercer Mundo, noticias de la actuación de la asociación en Murcia, poemas, y consejos varios, entre ellos de higiene.

MENSAJER $A^{18}$ es una Hojita de la Juventud Católica de Yecla, cuyo lema es «Piedad, Cultura y Trabajo», y que recoge solamente noticias de la asociación. ELPROPAGADOR EUCARISTICO ${ }^{19}$ es el Boletín del Consejo Diocesano de la Adoración Nocturna, y también su contenido es para la propia organización y piedad de los miembros. Algunas referencias políticas tiene NUESTRA FIES$T A^{20}$, periódico propagador de la devoción al Sagrado Corazón de Jesús, editado en Ribera de Molina desde 1922; estas referencias son solamente para pedir al Sagrado Corazón que se acaben las turbulencias sociales. Igualmente ocurre con algunos artículos de NUESTRO APOSTOLADO21, órgano de la Guardia de Honor y de la Congregación de Caballeros de la Fuensanta, de Murcia, que también cuenta con dos artículos sobre que «Los gobiernos liberales no son amigos del pueblon, (porque facilitan que la prensa ataque a la religión, facilitan los espectáculos y el vicio, e impiden manifestaciones públicas de culto), y en contra de la masonería, (que vive a costa del dinero del pobre pueblo).

EL MONASTERIO DEL NIÑO ${ }^{22}$, revista mensual religioso-histórico-mulefia, fundamentalmente promueve la devoción al Niño de Mula, la recolección de limosnas, y el fervor piadoso. Pero cuenta con algunos artículos sobre la ley del divorcio, sobre «La Iglesia y la libertad», contra la ley de la escuela laica, una circular del obispo de Tuy contra la propaganda masónica, y numerosas arengas para votar en cristiano en las elecciones de 1936. El número 25, de 1 de enero de 1935, da cuenta de la desaparición de El Liberal: «Gracias a Dios ha

\footnotetext{
${ }^{17}$ AHMM, 22-A-16.

18 AHMM, 28-D-6.

19 AHMM, 28-D-6.

${ }^{20}$ AHMM, 25-B-3.

${ }^{21}$ AHMM, 28-D-6.

22 AHMM, 27-C-23.
} 
muerto «El Liberal» de Murcia (...) que se ha dedicado a propagar la impiedad y la inmoralidad».

Como nota curiosa, este comentario del $n .^{\circ} 6$, de 1 de junio de 1933 , que bien puede ser un análisis de la sociedad del momento: «MAGNO ACONTECIMIENTO REGIONAL. Lo ha sido la inauguración de servicios en la línea férrea de Murcia a Caravaca. Dios quiera que sea beneficiosa para la Región y que los hombres, en vez de luchas fratricidas en busca del enchufe, trabajen por su prolongación de Caravaca hasta Baeza».

\section{c) Prensa laicista}

EL LIBERAL $L^{23}$ y $L A R E G I O N^{24}$ son dos diarios que pueden incluirse en este apartado. La prensa católica suele poner como ejemplo de periódico anticatólico al primero, comparándolo con su (hermano de Madrid». En sus páginas encontramos apartados dedicados a la vida religiosa y al culto, con horarios de misas, festividades, y todo tipo de actos, lo cual es lógico si el periódico quiere llegar a calar en una sociedad de tradicional religiosidad como es la murciana.

Sin embargo, al referir noticias relacionadas con la religión ( $\mathrm{y}$ especialmente, con la jerarquía católica), El Liberal hace gala de una fina y demoledora ironía. Por ejemplo, en el número 9.898, de 9 de enero de 1931, un titular dice: «Lo que se puede hablar sobre el matrimonio. Nada menos que dieciséis mil palabras se han empleado en la confección de la Encíclica de Pío XI. Para decirnos unas cuantas cosas sobre esta ceremonia religiosa». $Y$ a continuación se resume fríamente la encíclica, sin informar de su título ni más datos que puedan ayudar a quien tenga intención de conocerla más a fondo.

En el número 9.904, de 16 de enero de 1931, tras el titular «Un bello discurso del Deán de Oviedo», se califica de «diabólica transformación del sermón de la Montaña» tal discurso, que no es otra cosa que la doctrina habitual de la Iglesia acerca de que no se deben alentar las revueltas, pero tampoco se deben sofocar las justas reivindicaciones del pueblo. El diario presenta estas ideas como un cambio personal del Deán acerca de lo que en teoría sería la actuación de la Iglesia en contra de los desórdenes públicos. Esto supone, o un desconocimiento total de la DSI o un afán de alejar a la Iglesia «oficial» de la lucha obrera, exponiendo la DSI como opiniones personales y «diabólicas» de un deán asturiano.

\footnotetext{
${ }^{23}$ AHMM, 194-A a 195-A-8.

24 AHMM, 195-C.
} 
Otro error de expresión inconsciente o intencionado se encuentra en un titular del dos de enero de ese mismo año, n. ${ }^{\circ}$ 9892, que dice: «El Papa podrá acuñar moneda en Italia», aunque luego en el desarrollo de la noticia se entiende que será la moneda del nuevo estado Vaticano, y que por tanto no es un privilegio dentro del estado italiano.

Pero también hay noticias religiosas que se dan sin añadir ningún matiz. El sábado 17 de enero del 31 , en el $\mathbf{n} .^{\circ} 9.905$, el titular dice «Una carta al Jefe de Gobierno. El Cardenal Primado pide que se aumenten los haberes del cleron, y a continuación se resume el contenido de la carta, con todos los razonamientos del Cardenal, sin hacer ningún juicio de valor ni implícito ni explícito.

La Región. Diario de la República, y nacido con ella, sigue esta misma línea. En el n. ${ }^{\circ} 118$, de 1 de julio de 1932, hay un artículo firmado por Ramos de Sotomayor, titulado «Ceremonias con dignidad y dignidad sin ceremonia». Se refiere a la necesidad de arbitrar un ceremonial para las bodas civiles, para que los contrayentes no usalgan del juzgado bajo la penosa sensación de intrascendencia que deja hoy en su espíritu el destartalado ambiente oficinesco y la sequedad burocrática del funcionariado». Por contra, considera que la dignidad interior del matrimonio civil es mayor que la del matrimonio canónico pese al ceremonial de este último, el cual ridiculiza a través de su descripción.

Al día siguiente La Región recoge la noticia de una posible curación milagrosa en Lourdes; la redacción es tan aceradamente irónica que desprestigia a Lourdes, a la Iglesia y a los médicos que se encargan de verificar el caso. En el número 130 comienza una serie de artículos sobre «La mujer y la República», firmados por Manuel Lasso de al Vega, que intenta convencer a las mujeres de que no se dejen influir por la religión, como si esto fuera una debilidad femenina, y ataca duramente la presencia de la religión en la vida pública, acusando a los eclesiásticos de buscar solamente beneficios políticos y dinero.

Pero la mayoría de noticias relacionadas con la religión en este periódico se refieren a sucesos (como el apuñalamiento de una monja en un asilo por parte de uno de los internos, o la celebración de la procesión del Carmen en Malagón, pese a haber denegado el permiso el gobernador); 0 a disposiciones legales, reseñadas con una frialdad que no puede menos que llamar la atención. En el ejemplar de 6 de julio de 1932, dentro del apartado "disposiciones de La Gacetas dedica más espacio al convenio de la Unión Postal Americana y España que a la disolución del Cuerpo Eclesiástico del Ejército, del que sólo dice: «Promulga también una ley declarando disuelto el Cuerpo Eclesiástico del Ejército».

También, como en El Liberal, cuando alguna comunicación pública de un eclesiástico conviene a sus fines, la publican sin retocarla, pero también sin explicarla en profundidad. Es el caso de una pastoral del Obispo de Múgica (Vitoria), en la que dice a los sacerdotes que no se metan en política desde el 
púlpito, porque esto perjudica a la religión. De nuevo hay un error de apreciación en lo que es doctrina habitual de la Iglesia, pues el hecho de no meterse en política no significa que los sacerdotes no deban formar la conciencia del pueblo en relación a la moral social y a la coherencia de vida en el momento de votar o actuar en política. La falta de matización en este tema supone que $L a$ Región está animando a los sacerdotes a hablar sólo de piedad, quiere hacer ver que hay un obispo que les manda callar en relación a todo lo colectivo, que la religión no debe de estar en la sociedad.

Dentro de la prensa laicista encontramos la que simplemente se dedica a ridiculizar a la Iglesia, a veces con base en hechos reales, a veces sin ella. Es el caso de CRITICÓN ${ }^{25}$. Semanario Festivo Defensor de la República, que comienza a publicarse en octubre de 1931.

En los pueblos, los periódicos laicistas son menos agresivos; EL PUERTO ${ }^{26}$, órgano del Partido Republicano de Puerto Lumbreras, apenas hace alusión a noticias religiosas; igualmente actúa NOSOTROS ${ }^{27}$, de Lorca, aunque en su número 28, de 28 de agosto de 1932 publica un artículo tomado del Heraldo de Madrid, firmado por un sacerdote, que se lamenta de que «la España monárquica y católica» no haya pedido clemencia para evitar el fusilamiento de Galán y García Hernández. Este artículo compara a esta España con la España republicana, toda bondad y civilización para con los condenados a muerte.

\section{d) Prensa de derechas}

Del periódico semanal ${ }_{\text {PRESENTE }}{ }^{28}$, de Cieza, se conservan los números 1 , (de 31 de marzo de 1935), n. ${ }^{\circ} 6,22,24,25,27,28,30,34$, y 37 . No presta una atención especial a las noticias religiosas, la mayor parte de su información es política. En el $n .^{\circ} 1$ aparece la noticia de la llegada a Murcia en tren del nuevo obispo, D. Miguel de los Santos Díaz Gómara. En el número 22, en un artículo sobre la vida y escritos E. P. Salmerón, se reivindica la importancia de lo religioso al hacer la historia de los pueblos; sin la religión, considera el artículo, la historia se falsea y se mutila. En algunas ocasiones anima a sus lectores a luchar «Por Dios y por España».

De todos modos, dedica dos números monográficos a temas religiosos de carácter local: el n. ${ }^{3}$, está íntegramente dedicado al Cristo del Consuelo, cuyas

${ }^{25}$ AHMM, 22-A-5.

26 AHMM, 28-D-6.

${ }^{27}$ AHMM, 27-C-22.

${ }^{28}$ AHMM, 25-B-2.

Actas del I Congreso de Historia de la Iglesia y el Mundo Hispánico Hispania Sacra, 52 (2000) 
fiestas se celebran en Cieza; se compone de poemas y estudios dedicados a esta advocación. Lo mismo ocurre con el $n$. $^{\circ} 28$, de 20 de octubre de 1935 , que se dedica por completo a las Fiestas Cívico-religiosas en honor de Nuestra Señora de la Consolación, de Molina de Segura, lugar donde, desde el n..$^{\circ} 24$, se fecha la publicación, aunque siga conteniendo en su mayoría noticias de Cieza.

También en Cieza Acción Popular cuenta con un periódico semanal rotulado con el nombre del pueblo. En el número 15 (de 15 de mayo de 1932), se recoge un eco de la polémica de los crucifijos, con el título: «QPueden ostentar el crucifijo los niños de las escuelas nacionales?», y firmado por la Redacción. En él se explica que muchos padres del pueblo habían pedido a Cieza que se pronunciase a favor de dicha ostentación, pero que el semanal había decidido no decir nada "por si "alguien" nos denunciaba como boycoteadores (?) de la República». Sin embargo, el Ministro de Instrucción de la República, Fernando de los Ríos, había contestado a una pregunta sobre el tema hecha por el diputado Gil Robles, anunciando que se habian dado instrucciones a los maestros para que no confundan el laicismo con no dejar a los nifios lucir las cruces y medallas fuera de la ropa. Con ese comunicado, Cieza se sentía fuerte para apoyar a los padres del pueblo sin peligro de ser atacado.

El número 16 dedica su primera página a la festividad del Corpus Christi, con una serie de poesías religiosas de tipo sentimental. En el $n .^{\circ} 17$ da cuenta de un ataque a la libertad religiosa por parte de un personaje del ayuntamiento: «La procesión del viático a los impedidos. La autoriza el alcalde y en su ausencia la prohibe el teniente Dr. Ríos Gil». También incluye un artículo sobre la "Táctica socialista», incidiendo en el ataque de las izquierdas a la religión.

En Mula aparece en 1932 el Semanario Tradicionalista $L A C A M P A N A^{29}$, que se presenta con el lema: «Todo bajo el amparo de la Fe Católica y para defender el Reino de Cristo y combatir a sus enemigos sin descanson. Entre las diversas noticias locales, de actividades, fallecimientos, etc., La Campana cuenta con artículos que divulgan la doctrina de la Iglesia, junto a la doctrina política del tradicionalismo: Dios, Patria y Fueros. Sus artículos tienen varias temáticas:

1) De la DSI, (yendo expresamente en contra del materialismo: $n .^{\circ} 2$ ); se hacen eco de documentos de la jerarquía como el manifiesto de los Obispos sobre la ley de Comunidades Religiosas, al que añaden las declaraciones de Unamuno sobre la falta de libertad religiosa que dicha ley supone (n. $\left.{ }^{\circ} 4\right)$; sobre la polémica de los maestros y el crucifijo en las escuelas (n. $\left.{ }^{\circ} 19\right)$; sobre el matrimonio civil; una reseña de la encíclica de Pío XI Charitate Christi compulsi (n. $\left.{ }^{\circ} 20\right)$.

${ }^{29}$ AHMM, 25-B-2. 
2) Un larguísimo artículo separado en varios de los números, firmado por Armengol, rebatiendo a quienes atacan al catolicismo por considerar que es un retraso histórico para la civilización.

3) Diagnósticos sobre la situación contemporánea o sobre la necesidad de actuar, como uno acerca de la juventud católica $\left(n .^{\circ} 2\right)$, una resef́a sobre la importancia de la Prensa Católica ( $\left.\mathrm{n}^{\circ} 24\right)$, además de, al igual que otras publicaciones, anima a la gente a actuar en este momento, e invita a comprar en tiendas notoriamente católicas y hagan saber que van a ellas por ese motivo.

4) Sobre festividades concretas como S. José o la Resurrección.

Desde el número 25 , la última página se dedica a los obreros con el nombre de El Campanón, autotitulado «Organito de trabajadores, ni redimidos, ni redentores», que fundamentalmente ejerce de crítico con la labor del Ayuntamiento.

\section{e) Prensa de izquierdas}

La prensa de izquierdas hace habitualmente caso omiso a la religión, apenas gasta papel en atacarla. No incluye noticias, pero sí algunos artículos intentando cuadrar la doctrina de Cristo con el marxismo.

MERCANTIL $L^{30}$, FUE $^{31}$, OFENSIVA ${ }^{32}$ y NORMA $S^{33}$ comenzaron a publicarse durante la guerra. También incluimos en este grupo la segunda época de RADIO MURCIA. OFENSIVA es un Semanario portavoz de la Comisión Ejecutiva Provincial de la Juventud Socialista Unificada. Contiene sobre todo frases de Carrillo y Lenin, y arengas para mejorar la producción con vistas a sostener y ganar la guerra. FUE, como su nombre indica, es el órgano de la Federación Universitaria Escolar Murciana, y en un artículo de su número 1, de octubre de 1938, considera que han heredado una Universidad subordinada al Vaticano, y que ahora el objetivo que hay que conseguir es hacer renacer «la cultura y la Universidad" y aplastar al fascismo.

Mercantil es la revista del Sindicato Único Mercantil, y responde de ella la CNT. Tiene artículos de doctrina anarquista sobre política, sobre la guerra y de tipo sindical, en ninguno hace referencia a la religión. NORMAS es el órgano del Sindicato Provincial de Trabajadores del Comercio, de UGT, que ve la luz

30 AHMM, 22-B-2.

3 AHMM, 25-B-3.

32 AHMM, 220-B-4.

33 AHMM, 220-B-2.

Actas del I Congreso de Historia de la Iglesia y el Mundo Hispánico

Hispania Sacra, 52 (2000) 
el 1 de mayo de 1937. Contiene muchas llamadas de ánimo para ganar la guerra, consignas doctrinales marxistas, y artículos. De ellos tienen referencias religiosas dos: uno que censura la actitud de los comerciantes, que no se sacrifican para la causa común de la guerra, sino que acaparan o venden fuera de la zona que tienen asignada para ganar más dinero. $Y$ apoyan sus acusaciones con un «Jesucristo arrojó del templo a los mercaderes!». El otro está tomado de $E l$ Nacional de Montevideo, y rubricado por Marcelino Domingo. Se titula «Entre la traición y la lealtad. Dios habla», y explica que Dios está de parte de la República y ha hablado en la muerte de Sanjurjo, en el ataque de hemiplejía del Papa después de recibir a un grupo de emigrados de la zona rebelde, en la derrota italiana en el frente de Guadalajara, en el hundimiento del buque España y en la muerte trágica de Mola.

La segunda época de Radio Murcia ${ }^{34}$, comienza en el momento en que la emisora es incautada «para servicio del Pueblo y del Gobierno legalmente constituído", al inicio de la guerra, hasta su fin en noviembre de 1937 por falta de papel para imprimir. No hace referencia a noticias religiosas, pero sí incluye algunos artículos acerca de puntos doctrinales del socialismo, y poemas leidos ante sus micrófonos a favor de la república unos, en contra del fascismo otros.

Anteriores al conflicto bélico son:

- LIBERTAD $D^{35}$, semanario obrero de crítica e informaciones, de Cieza, dirigido por José Ríos Gil, el teniente de alcalde que hemos visto en un apartado anterior prohibiendo la procesión del Viático, y que en los números que se han conservado no incluye ninguna referencia a noticia religiosa alguna;

- EL AMGO DEL PUEBLO ${ }^{36}$, órgano de la Agrupación Socialista y UGT de Molina de Segura, en su número 3, de diciembre de 1931, recoge un artículo de Mariano Caravaca en contra de «los poderosos», a los que acusa de haber «soliviantado corazones y en los que el germen de la religión cristiana se ha marchitado a causa de vuestra conducta». Les hace un llamamiento a cambiar para honrar a la patria. Considera la causa de los odios religiosos el «elemento caciquil» que, unido al «cavernicolismo paleolítico», sacan la espada por no aceptar los artículos de la Constitución sobre religión. En una esquina de este periódico se puede leer: «Si Cristo fue el primer socialista, como afirma cierto periódico republicano -y no a secas-, $\iota$ a qué partido pertenecían los que ordenaron, y los que permitieron, su muerte en la cruz?»).

\footnotetext{
34 AHMM, 22-A-2.

${ }^{35}$ AHMM, 25-B-2.

36 AHMM, 25-B-3.
} 
- JUSTICIA ${ }^{37}$, órgano de la Federación de Dependientes de Comercio y Banca, vinculado a UGT. En su número 20, de 1 de noviembre de 1930, en el artículo de Pedro Ferrer Pujol «La tierra, el cristianismo y el problema social» se lee: «Puede decirse que el socialismo no es más que el continuador de Jesucristo, o si se quiere, el aplicador de su doctrina a la organización social (...). Íntimamente religioso, sinceramente cristiano el Socialismo, no predica para el otro mundo, sino para éste». Y Vicente Lacambra, en el mismo número, rubrica un artículo titulado «Sentido religioso del Socialismo", en el que explica que el sentido de la palabra religión se ha desprestigiado «por haber encarnado a través del tiempo (salvo en los comienzos de las religiones) formas de despotismo y sombras esotéricas», y en estos momentos el socialismo tiene que limpiar esa palabra.

A estas publicaciones periódicas debemos añadir los diarios Nuestra Lucha $^{38}$, Confederación ${ }^{39}$, y Unidad ${ }^{40}$, que siguen las mismas pautas.

\section{f) Prensa independiente}

Por último, la prensa independiente cuenta con dos periódicos meramente deportivos, $G O L^{41}$, en el que el $90 \%$ de la información está dedicada el fútbol, y MURCIA DEPORTIVA ${ }^{42}$. Los Exploradores de Murcia tienen sus propios medios de expresión; de ellos nos queda $T A B U^{\prime 43}$, «portavoz escultista del Clan de la Gacela», que contiene información para la propia organización de los Scouts.

Las distintas asociaciones profesionales son las que más publicaciones tienen: Anales de la Universidad de Murcia, Boletines diversos (del Colegio de Veterinarios, del Instituto Provincial de Higiene, de la Provincia de Murcia, el Boletin Sedero Español y el Boletín Social de la Provincia), Estudios médicos y Noticias Médicas; Vida Jurídica; Eco Sartorial (de la Sociedad de Maestros Sastres de Murcia). También puede considerarse profesional RADIO MURCIA, órgano de la Emisora EAJ17, que además de la programación radiofónica incluye artículos sobre técnicas de radiodifusión y noticias relacionadas con ese

\footnotetext{
${ }^{37}$ AHMM, 22-A-5.

${ }^{38}$ AHMM, 195-B-18 A 22.

39 Ibidem.

40 AHMM, 220-C-2.

41 AHMM, 28-D-7.

${ }^{42}$ AHMM, 26-D-1.

43 AHMM, 22-B-7.
}

Actas del I Congreso de Historia de la Iglesia y el Mundo Hispánico Hispania Sacra, 52 (2000) 
mundo. $F A R O^{44}$, revista de la asociación profesional de Conductores de Automóvil y Obreros similares de Murcia, tiene un información puramente sindical, pero en algunos artículos ataca a la UGT.

Las revistas culturales se refieren todas a la cultura local: $E L B A N D O D E$ $L A H U E R T A^{45}$, publicación anual relacionada con las fiestas locales; $A M A N E$ $C E R^{46}$, revista de literatura y comercio de Águilas, publica muchos poemas y novelillas, entre las que se encuentran dos de tema religioso: una poesía a la Dolorosa, y un cuento titulado: «Adolescencia, Pasión y Muerte de un frailecito», que es una poética crítica a los asaltos a las iglesias y conventos; por último, destaca $A M B I E N T E^{47}$, una revista quincenal de «Literatura y Economía Social», que cuenta con firmas sefieras de la cultura murciana y que comenzó en diciembre de 1935 y terminó en julio de 1936. En su primer número publica un artículo de José Rubio Báguena que, bajo el título «La Religión, la Monarquía y el culto al Honor en la Edad Media» explica los orígenes de los blasones que adornan las fachadas de muchas casas de la ciudad, sin excesivo rigor histórico.

Ambiente contiene muchos artículos sobre temas culturales murcianos, y en ellos aparecen sin cesar referencias a la religión (arte, tradiciones, procesiones, el Asilo de Lourdes...), siempre tratados con respeto e incluso con piedad poética. En abril de 1936, Ambiente protesta por la supresión de las tradicionales procesiones de Semana Santa, «y no profundicemos en los motivos. Seguramente los tendrán; pero no creemos que en Murcia, donde se registran menos delitos de índole social y donde hay, hasta en los propios apasionados, un respeto religioso indiscutible, sea preciso interrumpir la tradición procesionals. A partir del número 12, de 15 mayo del 36, los artículos meramente culturales disminuyen y comienzan a aparecer artículos «docentes» bajo el epígrafe «Cuestiones sociales», sobre los Gremios medievales, la economía de Grecia y Roma, y desde el número 15, de pedagogía. Y en el número 14 , un consultorio de amor y grafológico, a cargo de Richard Love.

En el grupo de publicaciones informativas nos encontramos PATRIA $C H I C A^{48}$, con artículos de política municipal, concursos, lecturas para mujeres y para nifios; $L A R E G I O ́ N D E M U R C I A^{49}$, Semanario Ilustrado de la Vida de las Provincias de Albacete y Murcia, que pregona: «Este periódico no pertenece

\footnotetext{
44 AHMM, 28-D-8.

45 AHMM, 220-B-2.

46 AHMM, 28-D-8.

47 AHMM, 22-A-11.

48 AHMM, 22-B-1.

49 AHMM, 25-B-3.
} 
a partido político alguno, su lema es: Libertad, Justicia y respeto a las Leyes». Efectivamente cumple su programa. Dentro de su función de informar, aparece una importante entrevista al catedrático de la Universidad de Murcia Gómez Piñán, que incluimos en el anexo documental por su interés en relación a la polémica de la unión del poder político y la religión. En medio de una mayoría de voces pidiendo gobiernos laicos o confesionales, Gómez Piñán mantiene con claridad las propuestas del dualismo gelasiano católico, $y$ hace una certera crítica a la tradicional dependencia de la Iglesia española del poder civil.

También informativos son $A M A N E C E R^{50}$, de Molina de Segura, que, al igual que FRATERNIDAD ${ }^{51}$, de Murcia, se titulan independientes de partidos, pero no sin ideología, ya que defienden los derechos de la Iglesia y la doctrina católica. Amanecer ofrece "cuestiones de interés y actualidad y sana doctrina moral»; a partir del número 4, en el editorial reconocen que se sienten continuadores de La Defensa, publicación de Acción Nacional que ha desaparecido; poco a poco se van radicalizando.

Publica varios artículos en contra de las teorías marxistas: uno firmado por D. Facundo en el que explica que la teoría de plusvalía de Marx supone el estancamiento de la industria, y más adelante escribe otro en el que anima a conseguir que los obreros no renieguen de la fe católica porque vean que los burgueses la defienden por interés; otro de P. Vicente, S. J., sobre «Catolicismo y Socialismo", en el que sale al paso de la apropiación de la doctrina de Cristo por parte de las izquierdas; una serie de artículos firmados por Laayb, sobre el colectivismo; otro de Pedro Ramón Martínez sobre el fracaso de las asociaciones de izquierdas por error de doctrina y de procedimiento (el primero es un error extranjero, y el segundo, español)...

Cuenta con artículos de dos mujeres: Consuelo Larrosa, que pone a las mujeres alerta contra la ley del divorcio, porque eso va a permitir que los maridos las abandonen, y escribe sobre temas culturales como el evolucionismo, la defensa de la agricultura como creadora de riqueza; y María Pilar, que en el artículo «Caridad o envidia» explica el modo cristiano de dar todo a los pobres, «cosa que dice y no hace el socialismom. Un obrero, José Castaño, escribe habitualmente artículos sobre, por ejemplo, la imposibilidad de «ser honrado sin Dios». La necesidad de la cultura para vencer al escepticismo, la denuncia de aquellos que usan el catolicismo para medrar, noticias sobre los ataques a propiedades 0 personas eclesiásticas... Es una publicación muy combativa, con mucho contenido, muy profunda y nada amiga de los paños calientes.

${ }^{50}$ AHMM, 25-B-3.

${ }^{51}$ AHMM, 220-B-2.

Actas del I Congreso de Historia de la Iglesia y el Mundo Hispánico

Hispania Sacra, 52 (2000) 
Fraternidad, por su parte, solamente incluye algunos artículos piadosos (sobre los siete domingos de S. José) o noticias sobre leyes que afectan a los católicos, o sobre el movimiento obrero.

Por último, hemos de resefiar tres publicaciones de crítica política, que en ningún momento toman partido en el tema religioso: $L A P A T R I A C H I C A^{52}$, revista semanal de política, arte, literatura, deporte, reportajes e informaciones, como se define, $L A$ GUERRILLA ${ }^{53}$, revista semanal de Cultura Política Popular Independiente, cuyo ideario es «naturaleza y sentido común»; y el semanario satírico DON CRISPIN $N^{44}$, que en su presentación dice: "i $\mathrm{Y}$ del problema religioso? -No quemaré incienso ni azufre en los altares de la conciencia, porque los olores fuertes y penetrantes molestan hasta a los chatos, y yo escribo para narices correctas». Aunque esta declaración de principios no es para nada respetuosa con la Iglesia, el semanario cumple muy bien sus objetivos de no entrar en ese tema, salvo algún que otro chiste como el siguiente anuncio: «Cura radical. Disfrazado de paisano, se ofrece para enseñar a domicilio la doctrina cristiana a los niños de los republicanos-católicos-vergonzantes. Economía y reserva». Todo un diagnóstico.

\section{CONCLUSIONES}

El estudio de estas publicaciones nos permite hacer las siguientes deducciones:

- La sociedad de Murcia en los afios de la Segunda República no era una sociedad muy politizada; tenía sus intereses más en asuntos profesionales, culturales y espirituales. Conforme se acerca la guerra civil va politizándose más, pero no por una mayor presencia social de los elementos «politizantes», sino por silencio de los demás.

- Dentro de quienes tenían intereses ante la opinión pública, destacan los oficialmente católicos, los sindicatos católicos y los periódicos de derechas. Los primeros buscan como público a todos los habitantes, los segundos a sus propios incondicionales.

- En la Región de Murcia, conforme bajamos hacia el sur y a la zona de contacto con Andalucía, disminuye la prensa católica y aumenta la prensa más

\footnotetext{
52 AHMM, 22-B-1.

${ }_{53}$ AHMM, 22-A-9.

${ }^{54}$ AHMM, 24-E-2.
} 
preocupada por la política y la prensa de izquierdas. Conforme vamos al norte, nos encontramos cada vez más prensa católica y espiritual.

- Los esfuerzos de la prensa religiosa están, en su mayoría, dirigidos a formar las inteligencias de los católicos, dando datos y estudios profundos. Los de la prensa arreligiosa $o$ antirreligiosa están dirigidos simplemente a ridiculizar la religión, no intentan razonar los motivos.

\section{ANEXO DOCUMENTAL}

LA REGION DE MURCIA, Semanario Ilustrado de la Vida de las Provincias de Albacete y Murcia. $n .{ }^{\circ}$ 5, 16 de julio de 1930.

«En el Ateneo continuó anoche la discusión de la Memoria política de D. Eduardo Ortega y Gasset. En ella se destacó un sacerdote, catedrático de la Universidad de Murcia, D. Tomás Gómez Piñán, especialmente invitado por la Junta. Habló principalmente de la separación de la Iglesia y el Estado. de la que se mostró partidario. Los señores ateneistas, en su mayoria parece que se sintieron un poco defraudados de que D. Tomás Gómez Piñán no blasfemara en escena y llamase sinvergthenzas a los obispos. Por ello se decía anoche en los pasillos, que era un sofista y algunos que era un sootracosa. ¡Qué hemos de hacerle!.

\section{VISITA}

-Si, esperaban otra cosa. Yo me lo temía y había dicho a Fernando de los Ríos: lo primero que a mi no me interesa es la política.

- ¿Cómo puede ser esto?

-Entendámonos. No me interesaba en el sentido de que no era misión mía hablar de política en el Ateneo. Y, porque además creo que mucho más importante que el problema político es el problema religioso en Espafia.

- ¿Usted cree de veras que hay problema?

-Con relación al Estado, claro que lo hay. Para los espafioles, en sí no existe problema. Antes de hacer la revolución, con la que piensan en el Ateneo, es preciso hacer la revolución religiosa, que no es, como han entendido de un modo demasiado ingenuo, el que unos cuantos curas nos lancemos a la calle dando vaces, sobre la reorganización religiosa. Me parece inútil querer llegar a una libertad politica antes de conseguir la libertad religiosa.

- ¿Y su doctrina de separación de la Iglesia y el Estado en qué se basa?

-Se funda en que por la cantidad de privilegios de la Corona y por las demás regalías se da a la Iglesia una condición de Iglesia nacionalizada que la perjudica notablemente.

- ¿No ha censurado a usted nadie que en su intervención de ayer en el Ateneo hablara de los perjucicios que la unión de la glesia con el Estado originaba en aquella, y no de los trastornos que produce a este?

-Sí, me han hablado de eso. Yo no creí que entonces fuera el momento oportumo de hablar de ello, puesto que lo que pudiera tener de intersante mi intervención era para hablar de la Iglesia.

$-\downarrow Y$ si ahora provocáramos la oportunidad? ¿Tendría usted inconveniente en contestarme?

Actas del I Congreso de Historia de la Iglesia y el Mundo Hispánico Hispania Sacra, $52(2000)$ 
-Ninguno. Creo sinceramente que al Estado le causan grandes perjuicios al comprometerse a proteger a la Iglesia y el ejercicio de esa protección se traduce en una serie de pactos y privilegios que son restricciones a la libre actividad del Estado.

-Además del sentido oneroso que la tal unión supone para el Estado, ¿no?

-Indudablemente. Yo tengo la idea de que la religión es un servicio, y como tal, debe ser pagado por quienes necesitan de ese servicio. En la separación de la Iglesia Católica no viviría peor que ahora y se vigorizaría en la lucha por la libertad de cultos. La positiva decadencia de la Iglesia en España está fomentada, primero, en la incultura, porque siendo nuestro país de los más destacados en el mundo católico, quizá el más, nadie sabe nada de Teología, de Mística, de Derecho Canónico, de las disciplinas, en suma, que integran la religión. La segunda razón de la decadencia hay que buscarla en la indiferencia religiosa, nacida de la condición del catolicismo español; que descansa más que en sí en el amparo humillante del Estado.

- ¿Su doctrina no tiene ningún punto de relación con la de los tradicionalistas, que también pedian la separación?

-En absoluto. Vázquez de Mella veía en esto, simplemente, una cuestión política. Como el alto clero era un alfonsino. Mella vio la solución en una separación tan amplia que la Iglesia y el Estado no se tocaran sino en lo que fuera absolutamente estricto. Conviene que usted haga constar que cuando hablo de «separación» no quiero que se entienda una falta de ligamen jurídico, sino reducir la relación en tanto que sirva para suprimir mutuos obstáculos. Pirfán?

- ¿Usted no creerá que la forma de gobierno es consubstancial a la Religión, verdad sefior

-La alianza del Trono con el Altar puede ser necesaria al Trono; pero al Altar de ninguna manera.

$-\succsim Y$ qué ventajas e inconvenientes ve usted para la Iglesia católica, digamos «española», en la Monarquía y en la República?

-Las Monarquías, sobre todo las absolutas, o las que no tienen el freno de un respeto a la Constitución y a las representaciones populares, perjudican, contra lo que la gente cree, a la Religión, degenerando con usurpaciones los derechos de la Iglesia.

-Por lo tanto, la Religión no sufre con la Libertad.

-Todo lo contrario. En los Estados Unidos, donde la separación es mayor y más típica, la Religión prospera porque el que tiene ideas religiosas las tiene de un modo integral, no como aquí, donde los que dan más voces llamándose católicos no saben qué cosa es el catolicismo y creen cumplir yendo de vez en cuando a misa. La Iglesia debe aspirar a una labor educadora, de cultura, a entrar por la razón y no por la imposición como en Espafía, donde auxilian las procesiones con la Guardia Civil. La ley de Cristo es libertad.

- ¿Qué opina usted de la ensef́anza religiosa?

-Aqui no hay enseñanza religiosa. El noventa por ciento de la juventud está educada en colegios religiosos, donde no han aprendido ni el credo, y de donde desde luego salen sin saber qué cosa es el espíritu de la verdadera Religión.

-¿Qué impresión sacó usted de los pasillos del Ateneo?

Nuestro cura tuerce el gesto:

-jQué se yo! Balbontín me obligó a estar duro con él... ¡Caso interesante! Yo recuerdo que cuando estaba en el Seminario Ieía poesías suyas, admirables por cierto, sobre la Eucaristía; ahora está «ennusecido». Lo siento; yo soy un hombre liberal, y lo siento. Veo en él una preocupación religiosa que puede llevarle desde Rusia a la Adoración Nocturna.

Actas del I Congreso de Historia de la Iglesia y el Mundo Hispánico Hispania Sacra, 52 (2000) 
$-i$ Hombre!

-En cuanto a Sánchez Román, buen amigo mío, me reprochó como teorizante. Fue de los que creyeron que dije poco... A todos nos pasa algo de esto. El que es un izquierdista grande, decidido, no se preocupa de orientar a la juventud universitaria en los grandes problemas civilistas que verdaderamente suponen una renovación.

- ¿Por ejemplo?

-Muchos. La cuestión del matrmonio civil, que en realidad no existe en Espafia y sigue considerándose como un conocimiento. El divorcio, jtantas cosas!

César González-Ruano, Del Heraldo de Madrid. 12 de julio».

Actas del I Congreso de Historia de la lglesia y el Mundo Hispánico Hispania Sacra, 52 (2000) 